\title{
Fear of childbirth among pregnant women attending antenatal care in Arba Minch town, southern Ethiopia: a cross-sectional study
}

Tiruset Gelaw', Teklemariam Gultie Ketema², Kassaw Beyene², Mekdes Kondale Gurara ${ }^{3}$ and Gebresilasea Gendisha Ukke $2^{*}$

\begin{abstract}
Background: Fear of childbirth is one of the life challenges the women encounter during pregnancy. It is an important source of distress for the women and their families and also increases the odds of obstetric complications during childbirth. The aim of this study was to assess the magnitude of fear of childbirth and associated factors among pregnant women attending antenatal care at public health facilities in Arba Minch town, southern Ethiopia.

Methods: Institution-based cross-sectional study was carried out among pregnant women who attended antenatal care at public health facilities in Arba Minch from November 1st - 30th 2019. A systematic random sampling technique was employed to include the participants. Data were collected through a face-to-face interview by using a structured and pretested questionnaire. Wijma Delivery Expectancy Questionnaire was used to score fear of childbirth. Epi Data version 3.1 and Statistical Package for the Social Sciences version 25.0 software were used for data management. Descriptive and analytic analyses were done and statistical significance was declared at a $p$-value $<0.05$ and $95 \%$ confidence level in multivariable analysis.

Results: A total of 387 pregnant women have participated in this study. Forty (10.3\%) of the pregnant women had a low degree fear, 154(39.8\%) had a moderate degree fear, 98(25.3\%) had a high degree fear, and 95(24.5\%) had severe degree fear of childbirth. Unplanned pregnancy $(\mathrm{AOR}=2.30,95 \% \mathrm{Cl}: 1.12,4.74)$, current pregnancy-related complications $(A O R=6.24,95 \% \mathrm{Cl}: 2.72,14.29)$, and poor social support (AOR $=1.93,95 \% \mathrm{Cl}: 1.01,3.68)$ were factors significantly associated with severe degree fear of childbirth.

Conclusions: Almost three-fourth of the pregnant women in this study area had moderate to severe degree fear of childbirth. Tailoring counseling during antenatal care visits is needed to address those women who are at a high risk of considerable childbirth fear and its health consequences.
\end{abstract}

Keywords: Anxiety, childbirth, Ethiopia, depression, pregnancy, Wijma Delivery Expectancy Questionnaire, stress

\footnotetext{
* Correspondence: gebresilasea@yahoo.com

${ }^{2}$ Department of Midwifery College of Medicine and Health Sciences, Arba

Minch University, P.O. Box 21, Arba Minch, Ethiopia

Full list of author information is available at the end of the article
}

(c) The Author(s). 2020 Open Access This article is licensed under a Creative Commons Attribution 4.0 International License, which permits use, sharing, adaptation, distribution and reproduction in any medium or format, as long as you give appropriate credit to the original author(s) and the source, provide a link to the Creative Commons licence, and indicate if changes were made. The images or other third party material in this article are included in the article's Creative Commons licence, unless indicated otherwise in a credit line to the material. If material is not included in the article's Creative Commons licence and your intended use is not permitted by statutory regulation or exceeds the permitted use, you will need to obtain permission directly from the copyright holder. To view a copy of this licence, visit http://creativecommons.org/licenses/by/4.0/. The Creative Commons Public Domain Dedication waiver (http://creativecommons.org/publicdomain/zero/1.0/) applies to the data made available in this article, unless otherwise stated in a credit line to the data. 


\section{Background}

Childbirth is a normal physiological process that transforms the realities of the mother as well as relationships within and between families and generations[1, 2]. The path of childbirth is associated with both pain and happiness for the women and their families. Women face many challenges from the conception of their babies to the culmination of the childbirth process. Fear of childbirth (FOC) is one of the problems the women encounter during pregnancy and can be a source of distress for the women, their family, and their caregivers [3-5].

Fear of childbirth is described as feelings of uncertainty and anxiousness before, during, or after delivery by thinking the future labor and delivery or experiences of others' fearful responses to childbirth and labor pain [6, 7]. It is one of the common problems affecting women's health and wellbeing in their perinatal life [6]. The degree of severity of the fear of childbirth varies from individual to individual ranging from negligible to extreme fear [7-9]. It is estimated that FOC affects about $14 \%$ of pregnant women globally and reports from high-income countries indicate that about $10 \%$ of pregnant women are suffering from FOC which is of a severe degree[10]. Studies in Africa also showed a high prevalence of FOC ranging from 20-61.2\% [11-13].

As one study reported, women with severe FOC seeks more antenatal visit and sick leaves than women with low FOC and the costs for handling women with severe FOC can be as high as $38 \%$ than those for women with low FOC [14]. Fear of childbirth has been related to a lot of negative impacts on the physical and psychological wellbeing of a woman: complications during pregnancy, experiencing severe pain during labor and delivery, increased duration of labor, use of anesthesia during labor and increased risk of cesarean deliveries [15-19]. It is also associated with the fear of pain in general and previous difficult labor in particular. Studies indicated that inadequate pain relief during the previous childbirth is the most common reason for requesting a cesarean birth among parous women which can make the women to fear the childbirth process $[11,20]$. Women with severe FOC are also vulnerable to subsequent psychological complications such as anxiety and depression [19].

Even though the Ethiopian government focuses on maternal and child health there is still high maternal and infant mortality in the country. As the health care system for women typically focuses on physical health, less attention has been given for the psychological dimensions [21]. Moreover, the available studies about fear of childbirth were conducted in high-income countries and little is known regarding the problem in low-income countries. Since there are differences in cultural values about childbirth from society to society, culturally tailored interventions regarding FOC are required. Thought the problem needs urgent attention, as far as our knowledge is concerned, no study has been conducted in Ethiopia regarding FOC. This study was therefore assessed the magnitude of FOC and factors associated with it among pregnant women attending antenatal care at public health facilities in Arba Minch town.

\section{Methods}

Study settings, design, period and population

Institution-based cross-sectional study design was employed from November 1st - 30th 2019. The study was conducted in public health facilities in Arba Minch town. Arba Minch is the capital city of Gamo zone in south Ethiopia. The town is located about 495 kilometers south of Addis Abba, the capital of Ethiopia. There were 3 governmental health institutions (1 hospital, 2 health centers), in the town that provide antenatal car$\mathrm{e}(\mathrm{ANC})$ service for the women in and around the town [22]. This study was conducted at the public health institutions in the town. The source population was all pregnant women who attend antenatal care in public health facilities in Arba Minch town and pregnant women who attended antenatal care service in public health facilities in Arba Minch town during the data collection period were the study population.

\section{Inclusion and exclusion criteria}

Pregnant women who attended ANC service at public health facilities in Arba Minch town were eligible for the study. Women with medical problems or those with pregnancy related complications that affect the women's ability to give consent and respond to the questions were excluded.

\section{Sample size determination and sampling technique}

The sample size for the first specific objective was determined using single population proportion formula by using the prevalence of FOC from a relevant previous study which was $61.2 \%(p=0.612)[13]$ and tolerating a marginal error of $5 \%$, power of $80 \%\left(Z_{\beta}=0.80\right)$ and $95 \%$ confidence level of certainty $\left(z \alpha /{ }_{2}=1.96\right)$. As the calculated sample sizes for the second objective (associated factors) were less than that was computed for the first objective, we have used the sample size calculated for the first objective. By using the formula for a single population proportion the calculated sample size was 364.8. By adding $10 \%$ for possible non-response rate, the final sample size was $401.28 \approx \mathbf{4 0 1}$.

There are three public health institutions in Arba Minch town, two health centers and one general hospital. According to the information we got from the antenatal care service clinics of the health institutions, about 31 pregnant women visit the hospital and 8 pregnant women visit each of the health centers for antenatal care service daily. The total number of pregnant women who were expected to 
visit the antenatal care clinics during the data collection period was calculated and used to determine the interval. The total sample size was allocated proportionally to the three public health facilities according to their daily visit load. We then applied a systematic random sampling technique to include every two pregnant women available at the ANC clinics during the data collection period.

\section{Data collection}

Data were collected using structured and pretested questionnaire including Wijma Delivery Expectation/Experience Questionnaire (W-DEQ) and the Oslo social support scale through a face-to-face interview technique. Six midwives were participated in the data collection and supervision after taking training for two days.

The W-DEQ has been designed especially to measure FOC operationalized by the cognitive appraisal of the delivery. This 33-item rating scale has a 6-point Likert scale as a response format, ranging from ' not at all' (= 0 ) to ' extremely' $(=5)$, yielding a score-range between 0 and 165 . Item numbers $(2,3,6,7,8,11,12,15,19,20$, $24,2527,31$ ) have the reversed score for the calculation of the woman's individual sum score. Internal consistency and split-half reliability of the W-DEQ was checked and the Cronbach's alpha score was 0.932 .

Degree of childbirth fear was operationalized as: W-DEQ sum score $<38$ (low degree fear) W-DEQ of 38-65.9 (moderate degree fear), W-DEQ of $66-84.9$ (high degree fear) and W-DEQ $\geq 85$ (severe degree fear of childbirth) [23].

Oslo social support scale: is a three-item question which is used to assess psychosocial distress. The sum ranges from 3 to 14 and interpreted as a score of 3-8 (poor social support), 9-11 (moderate social support) and 12-14 (strong social support) [24].

\section{Data quality assurance and analysis}

The questionnaire was first prepared in the English language and translated into Amharic and then translated back to English in order to ensure its consistency. A pretest was done on $20 \mathrm{ANC}$ attendants at another hospital located near the study area. Every questionnaire was checked daily for completeness and accuracy by trained supervisors and principal investigators.

Data were entered into Epi Data version 3.1 after checking for completeness and exported to statistical package for social science (SPSS) version 25.0 for analysis. Descriptive statistical analysis was computed and presented by tables. Binary Logistic regression was used to find out the association between the explanatory and outcome variable. Multivariable Logistic regressions were used to find out the association between dependent and independent variables. Variables with a p-value of less than 0.25 in binary logistic regression were considered for the multivariate logistic regression analysis. A Multicollinearity test was done to check the correlation between independent variables. The model goodness of fit was tested using Hosmer and Lemeshow test which was 0.910 . The statistical association was evaluated using odds ratio at $95 \%$ confidence interval and a p-value less than 0.05 .

\section{Results}

Socio demographic status of the study participants

A total of 387 pregnant women were interviewed yielding a $96.5 \%$ response rate. The age of the participants was ranged from 18 to 42 years with the mean age of $27 \pm 5$ years. (Table 1 ).

\section{History of abuse and social support status}

Twenty-three $(5.9 \%)$ of the participants reported that they had a history of abuse in their lifetime and 191(49.3\%) had a husband's support during the current pregnancy. With regards to social support: 102(26.3\%) had poor social support, 191(49.3\%) had moderate social support and the rest 94(24.3\%) had high social support.

\section{Obstetrics characteristics of the participants}

More than half (52.5\%) of the study participants were in the third trimester of their pregnancy. The majority (87.2\%) of the parous women had given birth to the preceding baby via spontaneous vaginal delivery (Table 2).

\section{Magnitude of fear of childbirth}

Forty $(24.3 \%)$ of the pregnant women had W-DEQ sum score $<38$ (low degree fear), 154(39.8\%) had W-DEQ score of 38-65.9 (moderate degree fear), 98(25.3\%) had a WDEQ score of 66-84 (high degree fear), and 95(24.5\%) had severe degree fear of childbirth (W-DEQ $\geqq 85$ ).

\section{Factors associated with severe degree fear of childbirth}

As the health consequences of sever degree childbirth fear likely to be of significant importance, we have executed bivariate and multivariable analysis for severe degree fear of childbirth. Accordingly, the bivariate analysis showed educational status, parity, unplanned pregnancy, current pregnancy complications, no husband support for pregnancy and poor social support were factors associated with sever degree fear of childbirth. In multivariable logistic regression analysis, unplanned pregnancy, current pregnancy problems and poor social support were factors associated with severe degree fear of childbirth. Those women who had unplanned pregnancy were about 2 times more likely to have severe degree fear of childbirth compared with those with planned pregnancy $(\mathrm{AOR}=2.30$, $95 \%$ CI: 1.12, 4.74). Women who had current pregnancyrelated complications were about 6 times more likely to have severe degree fear of childbirth than those without 
Table 1 Socio-demographic status of pregnant women attended ANC at public health facilities in Arba Minch town, Southern Ethiopia, 2019 ( $n=387)$

\begin{tabular}{|c|c|c|c|}
\hline Variable & Category & Frequency & Percent \\
\hline \multirow[t]{6}{*}{ Age in years } & $18-19$ & 14 & 3.6 \\
\hline & $20-24$ & 121 & 31.3 \\
\hline & $25-29$ & 127 & 32.8 \\
\hline & $30-34$ & 97 & 25.1 \\
\hline & $35-39$ & 21 & 5.4 \\
\hline & $40-45$ & 7 & 1.8 \\
\hline \multirow[t]{2}{*}{ Residence } & Urban & 288 & 74.4 \\
\hline & Rural & 99 & 25.6 \\
\hline \multirow[t]{3}{*}{ Marital status } & Single & 21 & 5.4 \\
\hline & Married & 364 & 94.1 \\
\hline & Divorced & 2 & 0.5 \\
\hline \multirow[t]{6}{*}{ Occupational status } & Employed & 124 & 32.0 \\
\hline & House wife & 180 & 46.5 \\
\hline & Self-employed & 54 & 14.0 \\
\hline & Daily laborer & 9 & 2.3 \\
\hline & Student & 12 & 3.1 \\
\hline & Other $^{a}$ & 8 & 2.1 \\
\hline \multirow[t]{4}{*}{ Educational status } & No formal education & 28 & 7.2 \\
\hline & Primary education & 117 & 30.2 \\
\hline & Secondary education & 106 & 27.4 \\
\hline & College and above & 136 & 35.2 \\
\hline \multirow[t]{5}{*}{ Religion } & Orthodox Christian & 175 & 45.2 \\
\hline & Protestant Christian & 168 & 43.4 \\
\hline & Muslim & 24 & 6.2 \\
\hline & Catholic & 17 & 4.4 \\
\hline & Others $^{b}$ & 3 & 0.8 \\
\hline \multirow[t]{6}{*}{ Ethnicity } & Gamo & 190 & 49.1 \\
\hline & Gofa & 91 & 23.5 \\
\hline & Wolayta & 45 & 11.6 \\
\hline & Amhara & 25 & 6.5 \\
\hline & Oromo & 22 & 5.7 \\
\hline & Other $^{c}$ & 14 & 3.6 \\
\hline
\end{tabular}

${ }^{a}$ wood collecting, farmer, jobless, other ${ }^{\mathrm{b}}$ Adventist, Jehovah's witness, ${ }^{\circ}$ Konso, Gurage, Tigrie, Sidama, Zeyse

current pregnancy-related problems $(\mathrm{AOR}=6.24,95 \% \mathrm{CI}$ : $2.72,14.29$ ). Moreover, participants who had poor social support were about 2 times more likely to report severe degree fear of childbirth (AOR = 1.93, 95\%CI: 1.01, 3.68) (Table 3).

\section{Discussion}

In this study fear of childbirth among pregnant women attending ANC services in public health facilities in Arba Minch town was investigated. Since almost all pregnant women had some degree of childbirth fear, we used a WDEQ sum score of 85 or more as women having a severe degree (considerable) fear of childbirth and the discussion was based on this cut-off point. Accordingly, the proportion of women with a considerable fear of childbirth in this study was $24.5 \%$ (95\%CI: $20 \%, 29 \%)$. The finding from this study is similar to other studies conducted in Malawi (20\%), Iran (20\%) and Australia (24\%) [5, 12, 25]. However, the cut-off points used in this study $(\geq 85)$ and studies conducted in Malawi $(\geq 66)$ and Australia $(\geq 66)$ is different indicating that the burden of the problem is still higher among women in this study area. It is also higher than the findings from a study which included six European countries and has used similar cut-off point for severe degree of childbirth fear where the prevalence of FOC ranged from 4.5 among primigraviadae in Belgium to 15.6 among primigraviadae in Estonia[26] and a result from a recent study conducted in Kenya where the prevalence of severe degree of childbirth fear was $8 \%$ [27]. On the contrary, findings from studies conducted in India (45.4\%),[28] the United States of America (39.4\%)[29] and Turkey (82.6\%)[25] have shown higher burden of the problem than results from this study.

These discrepancies may be due to the differences in culture and attitudes towards childbirth, differences in health institutions structure, quality of ANC, and the difference in tools used to measure the degrees of fear. Moreover, the inconsistency with the cut-off points to define the degree of childbirth fear can also affect the difference in the magnitude of the problem. For instance, some studies used 50, other 66 , some 85 as cut-off point [26-28]. Overall we can see that fear of childbirth is common among pregnant women across the world but the way the problem is reported has subjectivity which needs common consensus.

In the current study, unplanned pregnancy was strongly associated with FOC, which is supported by findings from a study conducted in Turkey, a study from six European countries and a study from Bangkok[26, 30-32]. The reason behind this may be due to an increase in stress among women with an unplanned pregnancy in addition to pregnancy physiological maladaptation. It is likely that the pregnancies are close to the previous ones that there might be obstetrical cases that demanded spacing the regencies. Unplanned pregnancy means the woman has more likely to have another life plan and the co-existence of the two conditions might have increased the degree of fear among these women. This is also supported by another study conducted in Turkey where women with unplanned pregnancy had problems with adaptation to pregnancy, felt more pain during labor and were at high risk of depression during puerperium [33, 34].

The other factor which had significant association with FOC in this study was the presence of complications during pregnancy. Women who had pregnancy-related 
Table 2 Obstetrical characteristics of the study participants, Arba Minch town, Southern Ethiopia, $2019(n=387)$

\begin{tabular}{|c|c|c|c|}
\hline Variable & Response & Frequency & Percentage \\
\hline \multirow[t]{2}{*}{ Gravidity } & Primigraviada & 122 & 31.5 \\
\hline & Multigravida & 265 & 68.5 \\
\hline \multirow[t]{3}{*}{ Parity } & Nulliparous & 129 & 33.3 \\
\hline & Primiparous & 142 & 36.7 \\
\hline & Multiparous & 116 & 30 \\
\hline \multirow[t]{3}{*}{ Trimester } & First trimester & 03 & 0.8 \\
\hline & Second trimester & 181 & 46.7 \\
\hline & Third trimester & 203 & 52.5 \\
\hline \multirow[t]{4}{*}{ Mode of delivery of the preceding pregnancy $(n=258)$} & Vaginal birth with episiotomy & 74 & 28.7 \\
\hline & Vaginal birth without episiotomy & 151 & 58.5 \\
\hline & Instrument assisted vaginal birth & 12 & 4.7 \\
\hline & Caesarean delivery & 21 & 8.1 \\
\hline \multirow[t]{2}{*}{ Planned current pregnancy } & Yes & 348 & 89.9 \\
\hline & No & 39 & 10.1 \\
\hline \multirow[t]{2}{*}{ Wanted current pregnancy } & Yes & 373 & 96.4 \\
\hline & No & 14 & 3.6 \\
\hline \multirow[t]{2}{*}{ Problems during the current pregnancy } & Yes & 28 & 7.2 \\
\hline & No & 359 & 92.8 \\
\hline \multirow[t]{2}{*}{ Had history of abortion } & Yes & 17 & 4.4 \\
\hline & No & 370 & 95.6 \\
\hline \multirow[t]{2}{*}{ Obstetrical/medical problems during the previous pregnancy $(n=265)$} & Yes & 29 & 10.9 \\
\hline & No & 236 & 89.1 \\
\hline \multirow[t]{2}{*}{ Had history of stillbirth } & Yes & 13 & 3.4 \\
\hline & No & 374 & 96.6 \\
\hline \multirow[t]{2}{*}{ Had fear of medical intervention } & Yes & 270 & 69.8 \\
\hline & No & 117 & 30.2 \\
\hline \multirow[t]{2}{*}{ Husband support present } & Yes & 355 & 91.7 \\
\hline & No & 32 & 8.3 \\
\hline
\end{tabular}

complications during the current pregnancy have more likely to have a fear of childbirth than those who were not. This finding is supported by study findings from a study conducted in Turkey [31]. The possible justification may be due to inadequate individualized counseling that women should get and stress from rumors and information they gather from the previous experience or other women or media and thus increases level fear of childbirth. Fear of being dying, baby injury, poor control of the body, lack of trust in health care professionals, lack of confidence to give birth and others may also increase if adequate counseling was not given to those women with pregnancy-related complications. Other study also reported the positive correlations between childbirth fear, and other problems during pregnancy [35].

Moreover, pregnant women who had poor social support were more likely to have FOC. This is in line with the study done in six European countries (Belgium, Iceland, Denmark, Estonia, Norway, and Sweden), Finland and the United States [26, 29, 36]. Another study conducted in Norway also supports the findings [37]. The possible justification may be due to the strong support by family, neighbor, or midwives can strengthen women's belief that childbirth is a physiological and controllable process, and thus, result in psychological wellbeing and reduced fear of childbirth. For women who had support from husband, family, mother or motherin-law together with a trained midwife may reduce fear.

Bringing fear of childbirth into the light as a problem among Ethiopian women may be taken as the strength of the study as most of the people including the women in the country themselves have not been considering the situation as a problem. However, the main limitation of this study was that we could not assess some variables which might have an important association with the 
Table 3 Multivariable logistic analyses for severe degree fear of childbirth and associated factors among pregnant women, Arba Minch town, southern Ethiopia, 2019

\begin{tabular}{|c|c|c|c|c|c|}
\hline & \multirow[t]{2}{*}{ Variables } & \multicolumn{2}{|c|}{ Severe degree Fear of childbirth } & \multirow[t]{2}{*}{ COR $95 \% \mathrm{Cl}$} & \multirow[t]{2}{*}{ AOR $95 \% \mathrm{Cl}$} \\
\hline & & Yes (n, \%) & No $(n, \%)$ & & \\
\hline \multirow[t]{4}{*}{ Educational status } & No formal education & $10(35.7 \%)$ & $18(64.3 \%)$ & $1.88(0.79,4.5)$ & $0.96(0.36,2.55)$ \\
\hline & Primary education & $31(26.5 \%)$ & $86(73.5 \%)$ & $1.22(0.69,2.17)$ & $0.60(0.22,1.61)$ \\
\hline & Secondary education & $23(21.7 \%$ & $83(78.3 \%)$ & $0.94(0.509,1.73)$ & $0.79(0.30,2.09)$ \\
\hline & College and above & $31(22.8 \%)$ & $105(77.2 \%)$ & 1 & 1 \\
\hline \multirow[t]{2}{*}{ Parity } & Nulliparous & $38(29.5 \%)$ & $91(70.5 \%)$ & $1.47(0.91,2.38)$ & $1.61(0.94,2.74$ \\
\hline & Multiparous & $57(22.5 \%)$ & $201(77.9 \%)$ & 1 & 1 \\
\hline \multirow[t]{2}{*}{ Planned pregnancy } & No & $16(41 \%)$ & $23(59 \%)$ & $2.34\left(1.2,4.70^{*}\right.$ & $2.30(1.12,4.74)^{*}$ \\
\hline & Yes & $79(22.7 \%)$ & $269(77.3 \%)$ & 1 & 1 \\
\hline \multirow[t]{2}{*}{ Current pregnancy complication } & Yes & $17(60.7 \%)$ & $11(39.3 \%)$ & $5.57(2.5,12.34)^{* *}$ & $6.24(2.72,14.29)^{* *}$ \\
\hline & No & $78(21.75 \%)$ & $281(78.3 \%)$ & 1 & 1 \\
\hline \multirow[t]{2}{*}{ Husband support } & No & $11(34.4 \%)$ & $21(65.6 \%)$ & $1.7(0.78,3.65)$ & $0.84(0.36,1.99)$ \\
\hline & Yes & $84(23.7 \%)$ & $271(76.3 \%)$ & 1 & 1 \\
\hline \multirow[t]{3}{*}{ Social support } & Poor support & $38(37.3 \%)$ & $64(62.7 \%)$ & $1.94(1.04,3.63)^{*}$ & $1.93(1.01,3.68)^{*}$ \\
\hline & Moderate support & $35(18.3 \%)$ & 156(81.7\%) & $0.73(0.40,1.34)$ & $0.66(0.35,1.24)$ \\
\hline & Strong support & $22(23.4 \%)$ & $72(76.6 \%)$ & 1 & 1 \\
\hline
\end{tabular}

${ }^{*} p$-value $<0.05,{ }^{* *} p$-value $=0.001, A O R$ Adjusted Odd Ratio, COR Crude Odd Ratio, $\mathrm{Cl}$ Confidence interval

problem like the history of abuse/violence during pregnancy with the tool.

Overall, the findings from this study conveys a clear message to health managers and health persons working in the maternity area about where, when and how to act in order to reduce morbidities related to childbirth fear.

\section{Conclusions}

This finding showed a high magnitude of fear of childbirth in pregnant women in this study area. Complications in the current pregnancy, poor social support and unplanned pregnancy were the factors significantly associated with fear of childbirth. There should be special attention and counseling for pregnant women who have an unplanned pregnancy and pregnancy-related complications such as mal-presentations, pregnancy-induced hypertension, gestational diabetes mellitus, antepartum hemorrhage and multiple gestation. Early identification of expectant mothers with severe childbirth fear during pregnancy by health-care professionals to provide cognitive behavioral therapy and support for their psychological and physical health is important to decrease the next FOC complications. We strongly suggest family planning providers as well as ANC providers to give appropriate information about how to avoid unplanned pregnancies and what to do when this happened. As Ethiopia is a multi-ethnic country, we recommend more studies that include mixed methods and cover a wider area. We also suggest for researchers across the world to use consistent tools to evaluate fear of childbirth to have comparable findings and also conducting a systemic review in the area.

\section{Abbreviations}

ANC: Antenatal care; FOC: Fear of Childbirth; IQR: Interquartile range; SD: Standard deviation; W-DEQ: Wijma Delivery Expectation/Experience Questionnaire

\section{Acknowledgements}

Our appreciation goes to all the women who took part in this study and for their patience.

\section{Author contributions'}

TG, GGU, KB, MKG and TGK: conceptualized the study. TG and GGU led the analysis. TG: wrote the original draft with inputs from GGU, KB, MKG and TGK. All authors have reviewed and approved this final draft of the manuscript.

\section{Funding}

This study was funded by Arba Minch University (http://www.amu.edu.et) (grant number: GOV/AMU/TH/CMHS/MW/05/11). The funder played no role in the design of the study, data collection and analysis, interpretation of the data, and writing of the manuscript.

\section{Availability of data and materials}

The datasets used and/or analysed during the current study available from the corresponding author on reasonable request.

\section{Ethics approval and consent to participate}

Ethical clearance was obtained from the Ethical Review Committee of Arba Minch University, College of Medicine and Health Sciences. An official letter was written by the College of Medicine and Health Sciences to the respective health institutions. All the study participants were informed about the objectives and importance of the study. Also, the study participants were informed about the confidentiality of the information they provide. Written informed consent was taken from every study participant (all participants were 18 years old or more); the consent was read by the interviewers to those women who were not able to read. The respondents had full right to 
refuse participation or terminate their involvement at any point during the interview.

\section{Consent for publication}

Not applicable.

\section{Competing interests}

The authors declare that they have no competing interests.

\section{Author details}

${ }^{1}$ Department of Midwifery College of Medicine and Health Sciences, Wollo University, Dessie, Ethiopia. ${ }^{2}$ Department of Midwifery College of Medicine and Health Sciences, Arba Minch University, P.O. Box 21, Arba Minch, Ethiopia. ${ }^{3}$ School of Public Health College of Medicine and Health Sciences, Arba Minch University, Arba Minch, Ethiopia.

Received: 16 August 2020 Accepted: 28 October 2020

Published online: 07 November 2020

\section{References}

1. Beiranvand SP, Moghadam ZB, Salsali M, Majd HA, Birjandi M, Khalesi ZB. Prevalence of fear of childbirth and its associated factors in primigravid women: A cross-sectional study. Shiraz E-Medical J. 2017;18:11.

2. Bewley S, Cockburn J. Responding to fear of childbirth. The Lancet. 2002

3. Okumus F, Sahin N. Fear of childbirth in urban and rural regions of Turkey: Comparison of two resident populations. Northern clinics of Istanbul. 2017:4(3):247.

4. Mortazavi F, Agah J. Childbirth fear and associated factors in a sample of pregnant Iranian women. Oman medical journal. 2018;33(6):497.

5. Toohill J, Fenwick J, Gamble J, Creedy DK. Prevalence of childbirth fear in an Australian sample of pregnant women. BMC Pregnancy Childbirth. 2014 14(1):275.

6. Nilsson C, Hessman E, Sjöblom H, Dencker A, Jangsten E, Mollberg M, et al. Definitions, measurements and prevalence of fear of childbirth: a systematic review. BMC Pregnancy Childbirth. 2018;18(1):28

7. Wijma K, Wijma B, Zar M. Psychometric aspects of the W-DEQ; a new questionnaire for the measurement of fear of childbirth. J Psychosomatic Obstetr Gynecol. 1998;19(2):84-97.

8. Wijma K. Why focus on 'fear of childbirth'?: Taylor \& Francis; 2003.

9. Eriksson C, Westman G, Hamberg K. Content of childbirth-related fear in Swedish women and men-analysis of an open-ended question. The Journal of Midwifery Women's Health. 2006;51(2):112-8.

10. O'Connell MA, Leahy-Warren P, Khashan AS, Kenny LC, O'Neill SM. Worldwide prevalence of tocophobia in pregnant women: systematic review and meta-analysis. Acta obstetricia et gynecologica Scandinavica. 2017;96(8):907-20

11. El-Aziz SNA, Mansour SE-S, Hassan NF. Factors associated with fear of childbirth: It's effect on women's preference for elective cesarean section. Journal of Nursing Education and Practice. 2017:7(1).

12. Khwepeya M, Lee GT, Chen S-R, Kuo S-Y. Childbirth fear and related factors among pregnant and postpartum women in Malawi. BMC Pregnancy Childbirth. 2018;18(1):391.

13. Madiha MT, Azza MEA, Thorea MM. Anxiety and Fear Level toward Childbirth among Primigravida versus Multigravida. IOSR Journal of Nursing Health Science. 2019;8(2):36-44

14. Nieminen K, Wijma K, Johansson S, Kinberger E, Ryding E, Andersson G, et al. Severe fear of childbirth indicates high perinatal costs for Swedish women giving birth to their first child. Acta Obstetricia et Gynecologica Scandinavica. 2017 01/04;96.

15. Adams S, Eberhard-Gran M, Eskild A. Fear of childbirth and duration of labour: a study of 2206 women with intended vaginal delivery. BJOG: An International Journal of Obstetrics Gynaecology. 2012;119(10):1238-46.

16. Van den Bussche E, Crombez G, Eccleston C, Sullivan MJ. Why women prefer epidural analgesia during childbirth: the role of beliefs about epidural analgesia and pain catastrophizing. European journal of pain. 2007;11(3):275-82.

17. Alehagen S, Wijma B, Wijma K. Fear of childbirth before, during, and after childbirth. Acta obstetricia et gynecologica Scandinavica. 2006;85(1):56-62.

18. Mazúchová L, Škodová Z, Kelčíková S, Rabárová A. Factors Associated With Childbirth-Related Fear Among Slovak Women. Central European Journal of Nursing Midwifery. 2017;8(4):742-8.

19. Räisänen $S$, Lehto S, Nielsen $H$, Gissler M, Kramer M, Heinonen S. Fear of childbirth in nulliparous and multiparous women: a population-based analysis of all singleton births in F inland in 1997-2010. BJOG: An International Journal of Obstetrics Gynaecology. 2014;121(8):965-70.

20. Saisto T, Halmesmäki E. Fear of childbirth: a neglected dilemma. Acta obstetricia et gynecologica Scandinavica. 2003;82(3):201-8.

21. ICF CSA. Ethiopia Mini Demographic and Health Survey. 2016.

22. Arba. Minch town helath department population profile. 2019.

23. Zar M, Wijma K, Wijma B. Pre-and postpartum fear of childbirth in nulliparous and parous women. Scandinavian Journal of Behaviour Therapy. 2001;30(2):75-84.

24. Dalgard OSDC, Lehtinen V, Vazquez-Barquero JL, Casey P, Wilkinson G. Negative life events, social support and gender difference in depression. Soc Psychiatry Psychiatr Epidemol. 2006:41(6):444-51.

25. Serçekuş P, Vardar O, Özkan S. Fear of childbirth among pregnant women and their partners in Turkey. Sexual Reproductive Healthcare. 2020;24:100501.

26. Lukasse M, Schei B, Ryding EL, Group BS. Prevalence and associated factors of fear of childbirth in six European countries. Sexual Reproductive Healthcare. 2014;5(3):99-106.

27. Onchonga D, MoghaddamHosseini V, Keraka M, Várnagy Á. Prevalence of fear of childbirth in a sample of gravida women in Kenya. Sexual \& Reproductive Healthcare. 2020:100510.

28. Johnson AR, Kumar MG, Jacob R, Jessie MA, Mary F, Agrawal T, et al. Fear of childbirth among pregnant women availing antenatal services in a maternity hospital in rural Karnataka. Indian Journal of Psychological Medicine. 2019:41(4):318.

29. Mildren WG. Prevalence and Risk Factors for Fear of Birth in Pregnant Women in the United States 2018.

30. Kabukcu C, Sert C, Gunes C, Akyol H, Tipirdamaz M. Predictors of prenatal distress and fear of childbirth among nulliparous and parous women. Nigerian Journal of Clinical Practice. 2019;22(12):1635.

31. Sen E, Dal NA, Dağ H, Senveli S. The reasons for delivery: Related fear and associated factors in western Turkey. Nursing Practice Today. 2015;2(1):25-33.

32. Phunyammalee M, Buayaem T, Boriboonhirunsarn D. Fear of childbirth and associated factors among low-risk pregnant women. Journal of obstetrics gynaecology. 2019;39(6):763-7.

33. Karaçam Z, Önel K, Gerçek E. Effects of unplanned pregnancy on maternal health in Turkey. Midwifery. 2011;27(2):288-93.

34. Barton K, Redshaw M, Quigley MA, Carson C. Unplanned pregnancy and subsequent psychological distress in partnered women: a cross-sectional study of the role of relationship quality and wider social support. BMC Pregnancy Childbirth. 2017;17(1):1-9.

35. Hall WA, Hauck YL, Carty EM, Hutton EK, Fenwick J, Stoll K. Childbirth fear, anxiety, fatigue, and sleep deprivation in pregnant women. Journal of Obstetric Gynecologic Neonatal Nursing. 2009;38(5):567-76.

36. Rouhe H, Salmela-Aro K, Gissler M, Halmesmäki E, Saisto T. Mental health problems common in women with fear of childbirth. BJOG: An International Journal of Obstetrics Gynaecology. 2011;118(9):1104-11.

37. Størksen HT, Garthus-Niegel S, Adams SS, Vangen S, Eberhard-Gran M. Fear of childbirth and elective caesarean section: a population-based study. BMC Pregnancy Childbirth. 2015;15(1):221.

\section{Publisher's Note}

Springer Nature remains neutral with regard to jurisdictional claims in published maps and institutional affiliations.

Ready to submit your research? Choose BMC and benefit from:

- fast, convenient online submission

- thorough peer review by experienced researchers in your field

- rapid publication on acceptance

- support for research data, including large and complex data types

- gold Open Access which fosters wider collaboration and increased citations

- maximum visibility for your research: over $100 \mathrm{M}$ website views per year

At BMC, research is always in progress.

Learn more biomedcentral.com/submission 